\title{
Cutaneous reflexes in small muscles of the hand
}

\author{
M. R. CACCIA ${ }^{1}$, A. J. McCOMAS ${ }^{2}$, A. R. M. UPTON, AND T. BLOGG \\ From the Department of Medicine (Neurology), McMaster University Medical Centre, \\ Hamilton 16, Ontario, Canada
}

SUMMARY A study has been made of the responses of motoneurones innervating small muscles of the hand to electrical and mechanical stimulation of the skin. Both excitatory and inhibitory effects could be observed in the same muscle after a single stimulus to a given area of skin. The earliest excitatory and inhibitory responses are probably mediated by group III and the smaller group II afferent nerve fibres. A later inhibition results from activity in the larger group II fibres which are connected to cutaneous mechanoreceptors, especially those in the tips of the fingers and thumb. This late inhibitory reflex may operate through the fusimotor system. The possible roles of these reflexes are discussed in relation to previous investigations in man and the cat.

In recent years there has been an increasing interest in the reflex responses of human motoneurones to cutaneous stimuli. This interest is appropriate for aberrations in cutaneous reflex activity underlie some of the most important physical signs in clinical neurology. Indeed, possibly as a consequence of the great significance of the Babinski response, nearly all the studies on cutaneous reflex activity in man have been carried out on the leg. In this last respect the present study is different for it has been concerned with the arm and, in particular, with those motoneurones innervating the small muscles of the hand. One reason for this choice was the opportunity which it afforded for further analysis of the late waves evoked in contracting muscles by nerve stimulation (Upton et al., 1971). There is, however, a major experimental advantage in employing the arm rather than the leg for the study of cutaneous reflexes in man. This advantage depends on the fact that particularly strong reflex changes can be elicited by stimulation of the fingers and thumb. By using conventional techniques for recording from digital nerve fibres it is then possible to determine the properties of the afferent impulse volley responsible for the reflex effects. In this paper it will be shown that, following a cutaneous

1 NATO Reseach Fellow on leave from the C. Besta Neurological Institute, Milan.

2 Member of the Canadian MRC Group in Developmental Neurobiology. stimulus, a characteristic sequence of excitatory and inhibitory responses can be detected in small muscles of the hand. The nature of these responses, and the factors influencing their sizes, are discussed.

\section{METHODS}

SUBJECTS Observations were made in 16 men and women aged between 25 and 40 years who were in good health and had no history of neurological disease. Some of these subjects were examined on more than one occasion.

STIMULI For electrical stimulation of digital nerves the electrodes consisted of two strips of silver foil, $3 \mathrm{~mm}$ in diameter, which were coated with electrode jelly. The cathodal electrode was bent round the proximal phalanx, while the anodal one encircled the middle phalanx. When only the finger tip was to be stimulated the electrodes were two $6 \mathrm{~mm}$ diameter tin discs coated with jelly and fixed to the finger pulp with collodion or adhesive tape. For stimulation at other sites a fold of skin was pinched up and gripped by two spring-loaded clip-on electrodes. At all sites the stimuli were rectangular voltage pulses $50 \mu \mathrm{sec}$ in duration and delivered either 1.75 seconds apart or else randomly. In some experiments mechanical stimuli were used. They were applied manually using a probe which contained a gramophone cartridge; the output from this piezo-electric device triggered a master timing unit (Devices Digitimer, Model 3290). 
RECORDING Recordings from muscles were made with strips of silver foil, approximately $4 \times 0.6 \mathrm{~cm}$, which were coated with electrode jelly on their undersurfaces and fastened to the skin with adhesive tape. One strip served as the stigmatic electrode and was placed over the end-plate region of the muscle under study. The reference electrode was fastened over the muscle tendon or, in the case of a small muscle of the hand, around the terminal phalanx of a digit. A third silver strip was attached to the dorsum of the hand and served as an earth. In the text reflex activity has been attributed to certain muscles with the understanding that, because of the electrode positions and the nature of the voluntary contractions, these muscles were likely to have been the main, but not the only, sources of the electromyographic (EMG) activity recorded. In some experiments a unipolar concentric needle electrode (Disa 9013L0501) was employed to record the activity of single motor units.

In all subjects sensory nerve action potentials were recorded from the median and ulnar nerves at the wrist. The electrodes were chlorided silver discs, $10 \mathrm{~mm}$ in diameter, and mounted in a Perspex holder so that their centres were separated by $3.0 \mathrm{~cm}$. The muscle and nerve responses were fed through specially designed low-noise amplifiers, using a frequency response which was $3 \mathrm{~dB}$ down at $2 \mathrm{~Hz}$ and $10 \mathrm{kHz}$. With a superimposition technique alone it was possible to distinguish nerve action potentials as small as $1 \mu \mathrm{V}$. The potentials were displayed on a storage oscilloscope (Hewlett-Packard model 141B) and fed through a loudspeaker. In order to measure the intensity and time-course of a change in motoneurone excitability, potentials were rectified and then entered into a signal analyser (Hewlett-Packard model $5480 \mathrm{~B}$ with type $5486 \mathrm{~B}$ and $5488 \mathrm{~A}$ plug-in units). The analyser was triggered by the Digitimer and was used to average the muscle responses to at least 64 stimuli, unless stated otherwise in the text. During stimulation the subject was instructed either to relax the muscle under study completely or to contract it. The intensity of contraction could be controlled during the experiment by observing, on the analyser, the vertical displacement of the trace displaying the rectified and averaged muscle activity.

At the end of the experiment accurate determinations of the amount of inhibition or excitation were made by measuring the rectified EMG activity over $25 \mathrm{msec}$ epochs. The measurements were performed manually with a planimeter which was used to trace out the voltage-time integrals on photographs of the averaged responses. The EMG integral was then expressed as a percentage of the integrated maximal $M$ wave of the muscle under study.

In the text all mean values have been given with their standard deviations.

\section{RESULTS}

EFFECTS OF DIGITAL NERVE STIMULATION In all the subjects tested a search was made for excitatory or inhibitory effects after stimulation of a digital nerve. The demonstration of inhibition requires a special technique. One method which has been used in the triceps surae muscle for this purpose, that of H-reflex testing (for example, Gassel and Ott, 1970), is not applicable to the upper limb where H-reflexes
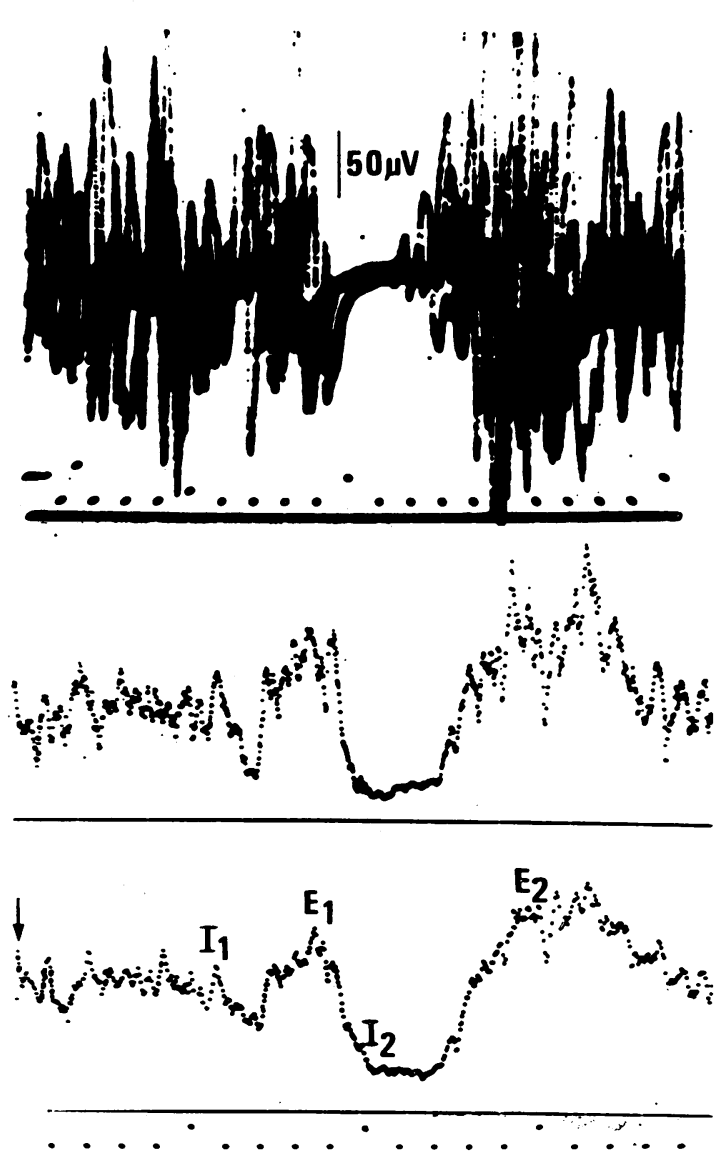

Fig. 1. Upper. Reflex responses evoked in abductor pollicis brevis muscle by electrical stimulation of index finger. Five oscilloscope traces have been superimposed. Middle. Average of 32 rectified responses recorded during continuation of the above experiment. Lower. Average of 64 responses. The onsets of the various waves have been identified (see text); arrow signals stimulus. Smallest divisions on time scales represe $n t$ $10 \mathrm{msec}$. 
are not normally demonstrable. The method which has been employed instead requires that the subject attempts to make a steady contraction; the occurrence of inhibition is signalled by a reduction in muscle activity. There are various ways in which the muscle activity can be recorded, of which the simplest is to superimpose EMG traces on a storage oscilloscope (Fig. 1, upper). While this technique will demonstrate the presence of relatively strong inhibition, it will not show up minor degrees nor will it enable determinations to be made of the intensity of inhibition, if this is less than total, or of the onset of inhibitory effect. For these reasons, an improved method of recording has been employed in which the EMG activity is first rectified and then entered into a signal averager (Gassell and Ott, 1970). In the absence of a stimulus the EMG activity averaged from a number of samples will approximate to a smooth horizontal trace. The vertical displacement of this trace from the base-line will be proportional to the intensity of the contraction. If a stimulus is delivered any inhibition of alpha-motoneurones will cause a temporary reduction in EMG activity. During this period the averaged record will approach the base-line and will reach it if the inhibition is complete. Conversely, any excitatory effects will cause the averaged trace to rise above the initial level, before stimulation.

With this technique all subjects could be shown to have a response to digital nerve stimulation, using an intensity which was supramaximal for the fastest-conducting group of nerve fibres. The most commonly observed response was a combination of inhibition and excitation and a typical example is shown in Fig. 1 (middle and lower). In this experiment responses were recorded from the abductor pollicis brevis (APB) muscle and the index finger of the same hand was stimulated. It can be seen that one inhibitory phase $\left(I_{1}\right)$ began approximately $58 \mathrm{msec}$ after the stimulus had been delivered and was succeeded by a weak excitatory phase $\left(E_{1}\right)$ at $75 \mathrm{msec}$. A second inhibitory phase $\left(I_{2}\right)$ commenced at $95 \mathrm{msec}$ and was terminated by a strong excitatory phase $\left(E_{2}\right)$ at 133 msec. When a slow sweep of the analyser was used several further alternating excitatory and inhibitory phases could be distinguished

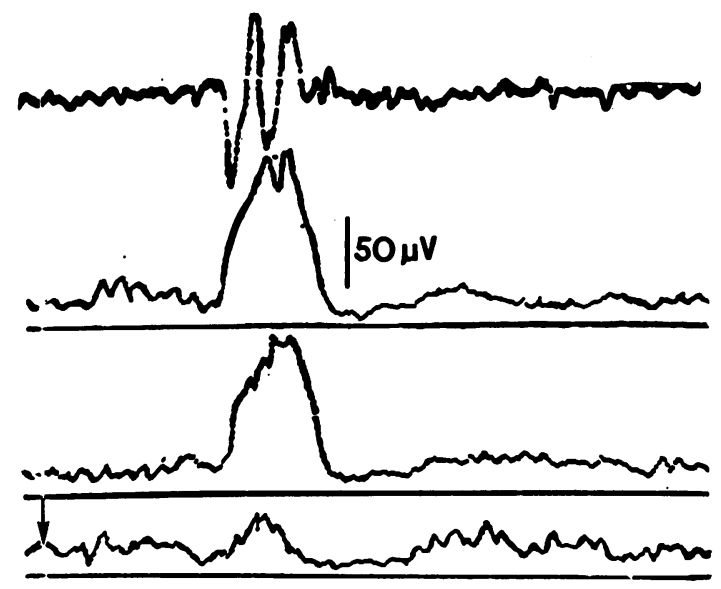

FIG. 2. Observations in a subject who displayed prominent $E_{2}$ responses in $A P B$ following stimulation of her index finger. The upper trace shows averaged EMG activity, while in the two middle traces the potentials have been rectified beforehand (16 responses in each instance). In these periods of observation theres was minimal background voluntary contraction. The $\underset{\square}{\mathbb{D}}$ lowest trace portrays results obtained during contraction of intermediate intensity and the ampli- $\mathrm{O}$ fication has been reduced by a factor of 5. Stimuluso shown by arrow. Smallest divisions on time scale represent $10 \mathrm{msec}$.

before a smooth contraction was resumed (for example, Fig. 8b).

The onset of $I_{1}$ wave-that is, the first component in this evoked activity-varied from $30-76 \mathrm{msec}$ in the population tested and was sufficiently early to suggest that it was reflex in origin and not consciously directed. This suggestion was tested by measuring the voluntary reaction time to the same stimulus in three subjects. For example, when the relaxed subject was told to move the thumb as soon as he felt the stimulus to his finger, the latencies varied from 120 to $160 \mathrm{msec}$ with a mean of $141 \pm 13 \mathrm{msec}$. If, however, the subject was performing a weak background contraction before the stimulus the mean latency was reduced to $123 \pm 8 \mathrm{msec}$ and the minimum value to $115 \mathrm{msec}$. When the subject was instructed to completely relax the muscle on perceiving the stimulus, the mean 
voluntary response time was $160 \pm 24 \mathrm{msec}$. For this latter test it was necessary to use subjects with incomplete 'reflex' inhibition, in whom a voluntary component could be searched for. The various reaction time measurements suggested that not only the $I_{1}$ wave but also the $E_{1}$ and $I_{2}$ components were reflex in origin.

The reflex responses described, those of wellmarked alternating excitation and inhibition, were found in 13 of the 16 subjects examined. In three of these subjects the initial excitatory phase $\left(E_{1}\right)$ was so strong that a response could be elicited from the muscle at rest or during very slight effort (Fig. 2); this latency varied from 50 to $75 \mathrm{msec}$. In a further three subjects, however, neither excitation nor inhibition were prominent. On the basis of serial observations on four subjects it was our impression that the cutaneous reflexes became more marked with repetition of the experiment and that some form of conditioning might have taken place.
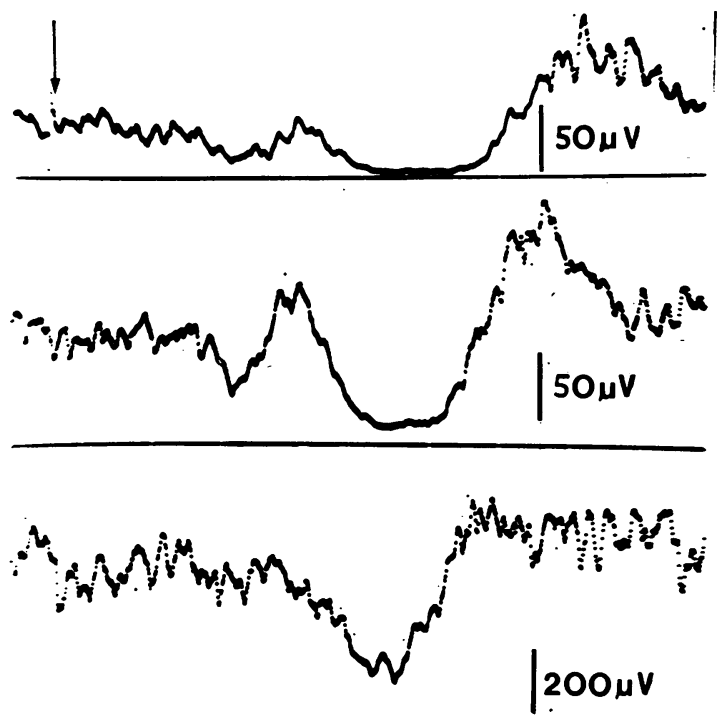

IG. 3. Effect of increasing voluntary contraction on $A P B$ muscle responses to electrical stimulation of the index finger (stimuli maximal for group II fibres). Results for experiments employing weak, intermediate and maximum strength are shown in the upper, middle, and lower traces respectively. Smallest divisions on time scale represent $10 \mathrm{msec}$.
EFFECT OF VOLUNTARY CONTRACTION The degree of voluntary contraction was an important factor in determining the size of the cutaneouslyinduced inhibitory reflex. This is illustrated in Fig. 3 which shows the results of an experiment in which the strength of voluntary abduction of the thumb was varied while the intensity of the electrical stimulus to the index finger was kept constant. It can be seen that during relatively weak effort the inhibition ( $I_{1}$ phase) commenced approximately $40 \mathrm{msec}$ after the stimulus was delivered. The maximal intensity of the inhibition was reached $95 \mathrm{msec}$ after the stimulus, during the $I_{2}$ phase; at this time there was almost complete suppression of volitional activity at about $118 \mathrm{msec}$. During stronger contraction

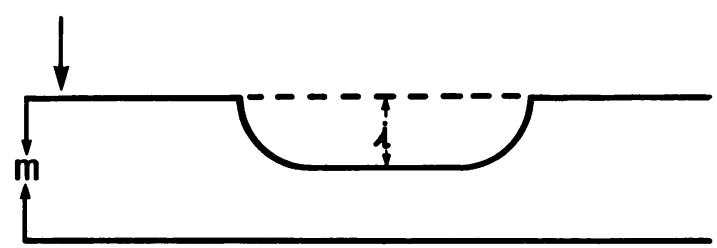

FIG. 4. Determination of the fraction of the motoneurone pool inhibited by cutaneous stimulation (see text).

the inhibition was unchanged in latency but finished sooner, at $111 \mathrm{msec}$. In order to study the effect of maximal effort without the complication of fatigue the last experiment was interrupted several times before the full number of sweeps was achieved for averaging. Figure 3 (lower) shows that, although the inhibition was unchanged in latency, it now began to decline earlier, at approximately $102 \mathrm{msec}$. It is also apparent from Fig. 3 that the intensity of the inhibition became less with increasing effort, since a greater proportion of the recruited motoneurones were able to continue firing. However, it is perhaps more relevant to consider the intensity of inhibition in terms of the total alpha motoneurone pool instead of the active fraction only. If it is assumed that the entire motoneurone pool is recruited during a maximal contraction (Merton, 1954) and if differences in the sizes and firing frequencies of motor units are ignored, then the fraction inhibited will be $i / m$ where $i$ is 


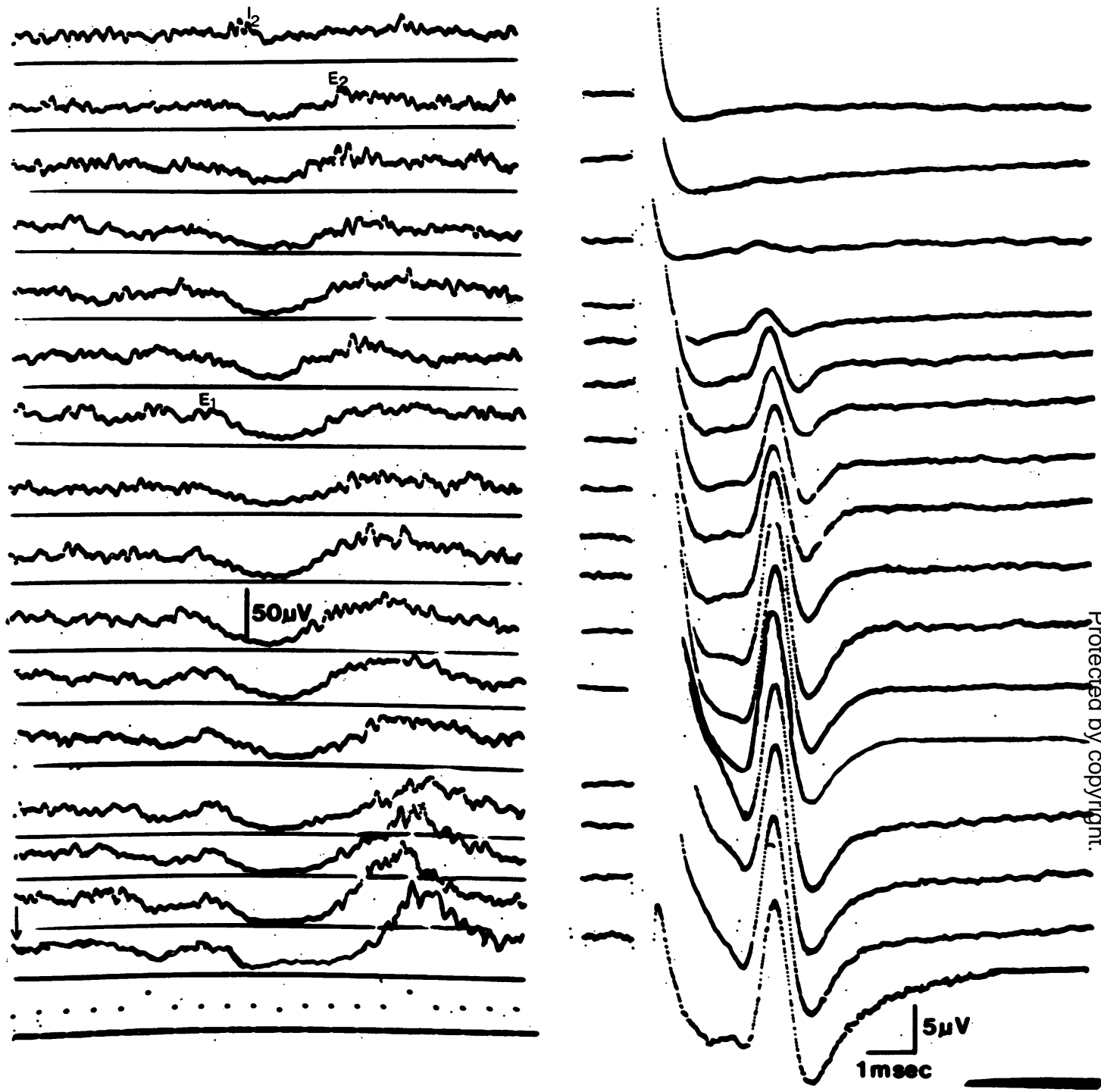

FIG. 5. On the left, from above downwards, are shown the effects of increasing stimulus intensity on the reflex responses. The stimuli were applied to the index finger and recordings were made from APB during contractions of intermediate strength. The corresponding sensory nerve volleys are shown on the right and were recorded from the median nerve at the wrist. The smallest divisions on the time scale (left) represent $10 \mathrm{msec}$.

the maximum drop in the averaged trace during the inhibitory period and $m$ is the vertical displacement of the averaged trace from the baseline during a maximum contraction, before inhibition (Fig. 4).

In the experiment under consideration $m$ was $0.55 \mathrm{mV}$ and during maximal voluntary con- traction $i$ was $0.30 \mathrm{mV}$; hence the fraction of the motoneurone pool inhibited was $0 \cdot 30 / 0 \cdot 55=0 \cdot 55$. For a weaker voluntary effort the corresponding fraction cannot be determined, for the inhibition could well affect motoneurones other than those $O$ actually employed in the contraction. Therefore $N$ the only certain conclusion to be drawn from this 


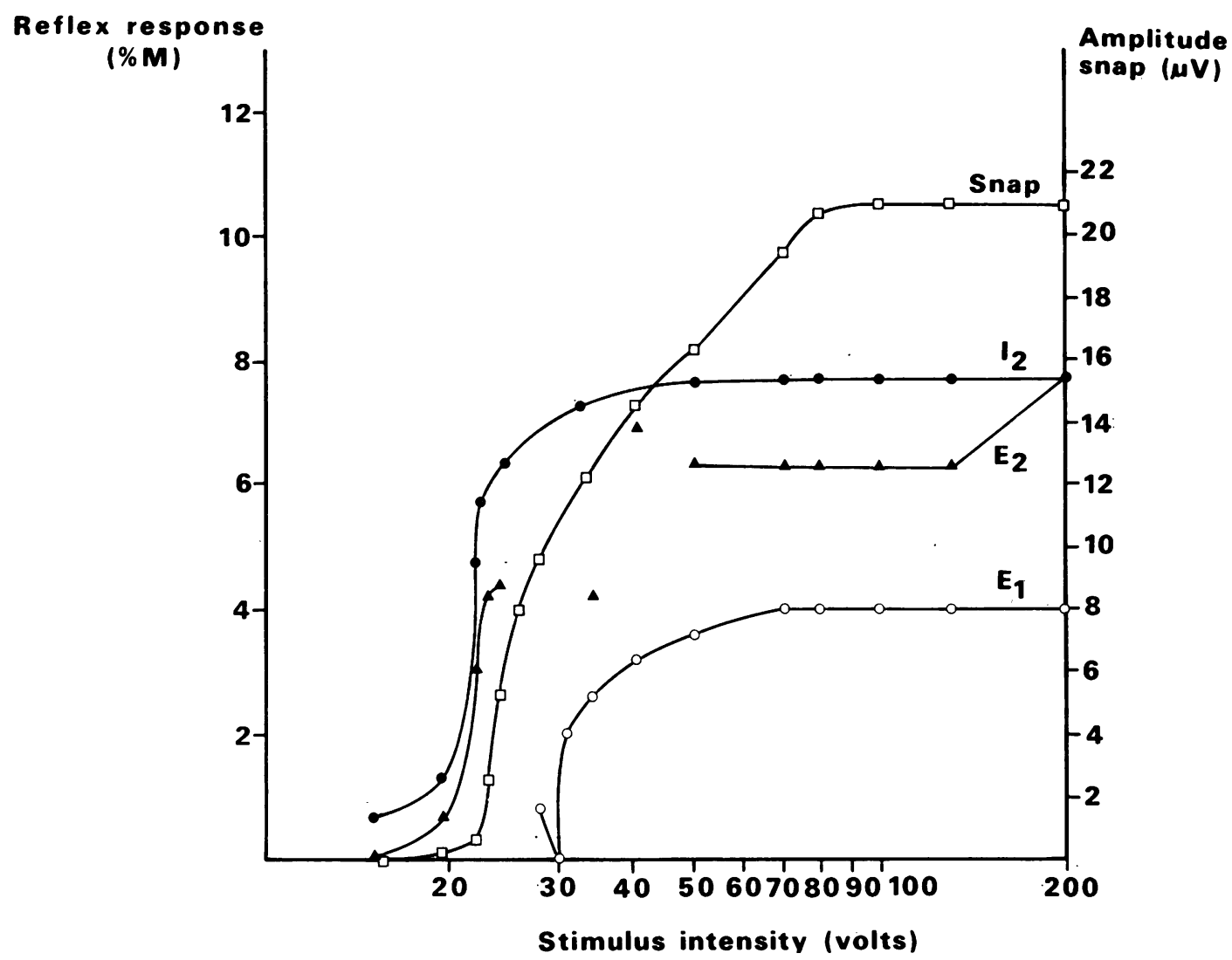

FIG. 6. Effect of increasing stimulus strength on the sizes of the median sensory nerve action potential (snap) and the $E_{1}, E_{2}$, and $I_{2}$ reflex responses. The reflex responses were measured as voltage-time integrals during 25 msec epochs and expressed as percentages of the maximal integrated $M$ wave. Note logarithmic scale of abscissa.

part of the experiment was that increasing effort can shorten the period of inhibition but cannot influence its time of onset. Because of the effect of voluntary contraction on reflex activity all the experiments to be described were performed using contractions of intermediate intensity.

EFFECT OF STIMULUS STRENGTH ON REFLEX ACTIVITY In all subjects the strength of the electrical stimulus to the index finger was systematically varied so as to alter the size of the impulse volley reaching the cord. It was found that both the excitatory and inhibitory components of the reflex were affected by this manoeuvre. Figure 5 shows the compound action potential recorded from the fastestconducting (group II) fibres of the median nerve at the wrist after graded stimulation of the index finger in a subject with prominent reflex responses; the Figure also displays the averaged EMG response from the abductor pollicis brevis (APB) muscle.

There is a suggestion that $I_{2}$ inhibition was already present (Fig. 5 top trace) when the stimulus was at the threshold for conscious appreciation, being felt on approximately half the occasions. At this low stimulus strength it was not possible to record a nerve action potential, even with an averaging technique. As the stimulus was increased the inhibition became more intense. By measuring the EMG voltagetime integral over a $25 \mathrm{msec}$ epoch it could be demonstrated that the intensity of the inhibition was maximal when $65 \%$ of the fast conducting 


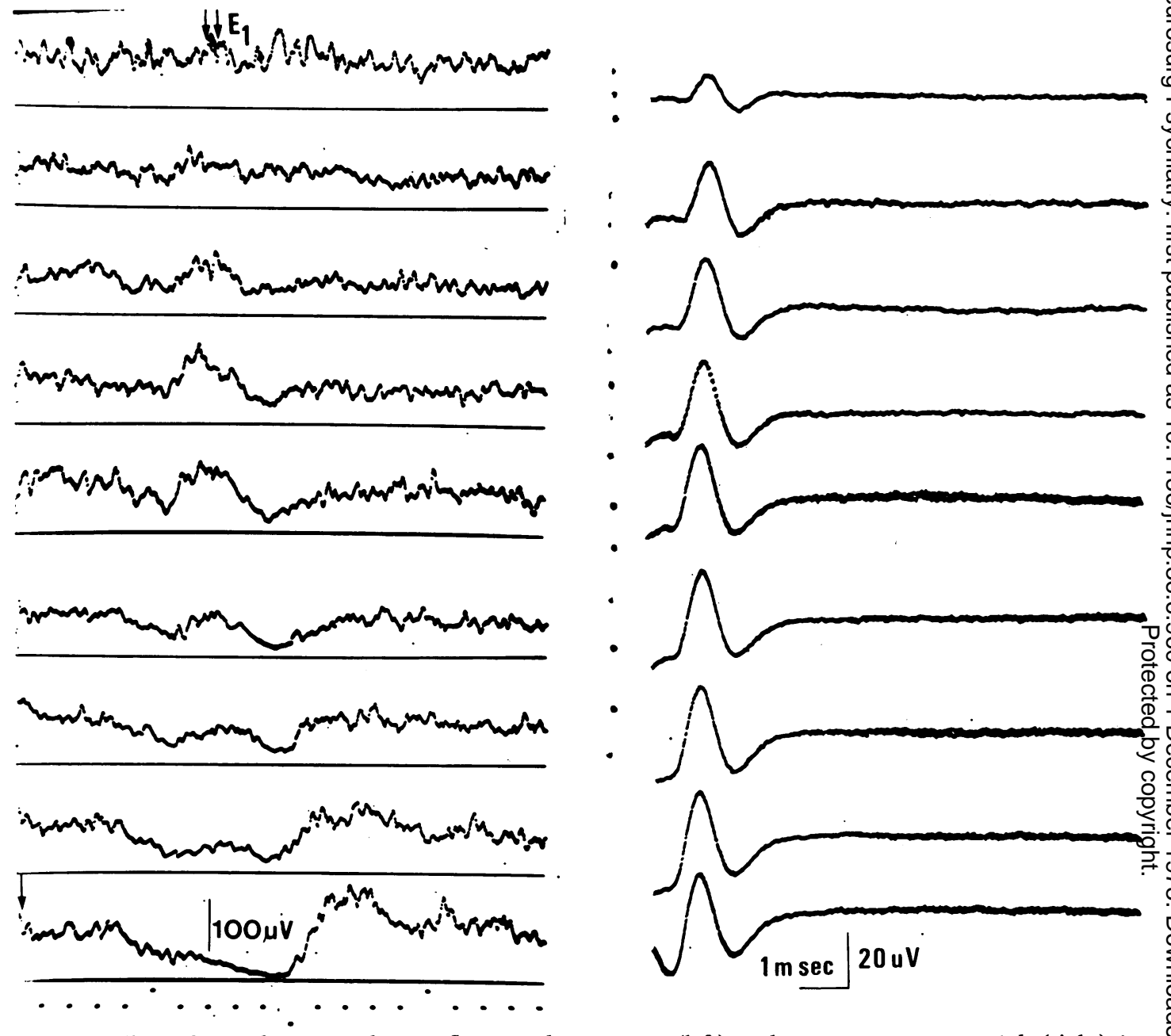

FIG. 7. Effect of stimulus strength on reflex muscle responses (left) and sensory nerve potentials (right) in $a \stackrel{\mathbb{Q}}{\circ}$ subject with a low-threshold $E_{1}$ wave (arrows, top trace). Recordings were made from the $A P B$ muscle and $\overrightarrow{\overrightarrow{0}}$ electrical stimuli to index finger were increased progressively (from above downwards in Figure). Smallest 3 divisions on time trace represent 10 msec. See text.

sensory fibres were activated (Fig. 6). In these experiments, in which no special precautions were taken to control limb temperature, the mean maximal impulse conduction velocity for nerve fibres from the index finger was $50 \pm$ $0.7 \mathrm{~m} / \mathrm{sec}$. Figure 5 also shows that as the stimulus was raised, the latency of inhibition shortened from 90 to $42 \mathrm{msec}$. Among the 16 subjects tested the shortest latency observed was $30 \mathrm{msec}$; the mean value for the group was $35 \pm 4$ msec. Inspection of Fig. 5 suggested that this early inhibition was a discrete phase separated from the later, and low-threshold, $\underline{3}$. inhibition by an excitatory period $\left(E_{1}\right)$. It is of 8 interest that in this subject the median nerve $₹$ action potential grew no further as the stimulus $\frac{\text { o }}{5}$ strength was increased and the early inhibition $\rightarrow$ developed. Indeed, in most subjects tested the threshold for $I_{1}$ inhibition was substantially $\tilde{O}^{\circ}$ greater than that for the $I_{2}$ type, though an exception is shown in Fig. 7.

The effect of stimulus strength on excitatory 


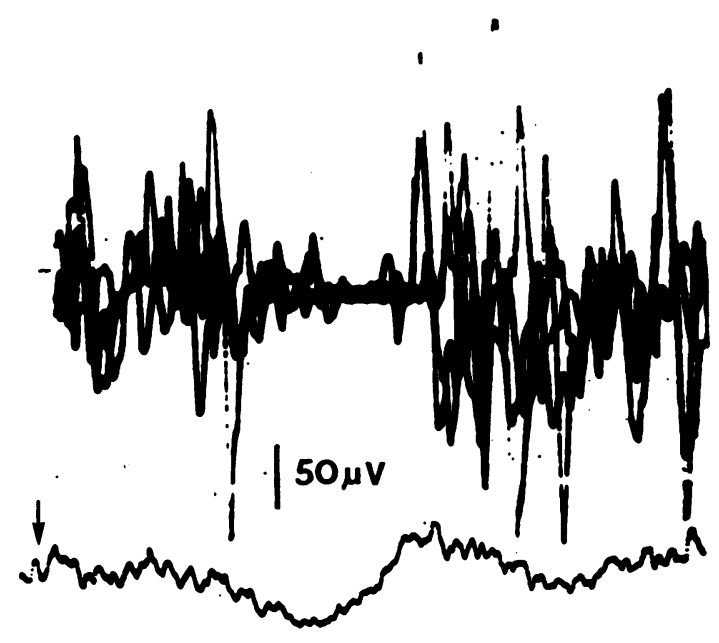

(a)

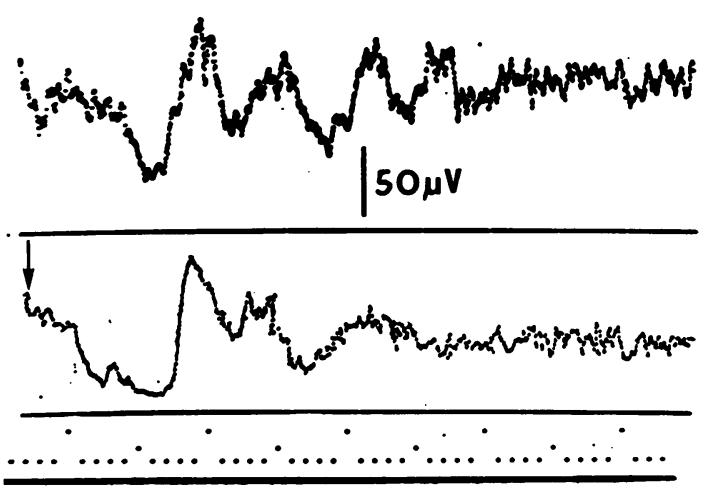

(b)

FIG. 8. (a) Reflex responses in APB after mechanical stimulation of the tip of the index finger, displayed as superimposed oscilloscope traces and as an average of the rectified activity. (b) Top trace shows averaged APB responses to mechanical stimulation recorded during ensuing 500 msec. Alternating phases of activity can be clearly seen. Lower trace shows responses to electrical stimulation of digital nerves in same finger. Smallest divisions on time trace represent 10 msec.

parts of the reflex was equally complex. The $\mathrm{E}_{2}$ excitatory component, starting immediately after the main inhibitory $\left(I_{2}\right)$ phase, had a relatively low threshold and became more prominent as the stimulus increased. Figure 6, which relates the size of $\mathrm{E}_{2}$ to stimulus strength, shows a plateau once approximately half of the 'fast' sensory fibres had been excited. A further increase in $\mathrm{E}_{2}$ was evoked when considerably larger stimuli were employed which were supramaximal for the 'fast' fibres (Fig. 6).

The early excitatory component $\left(E_{1}\right)$ usually had a higher threshold than $E_{2}$ and did not appear until a substantial fraction of the fastconducting axons had been activated (Figs 5 and 6). This was not so in all subjects, however, for in a few the $E_{1}$ response also had a low threshold (Fig. 7). In this last figure, as in Fig. 5, it can be seen that the $I_{1}$ and $E_{2}$ components continued to develop as the stimulus intensity was increased, even though the sensory nerve action potential, recorded from group II fibres, was maximal. Indeed, augmentation of the stimulus might eventually cause $E_{1}$ to become completely suppressed by the fusion of the $I_{1}$ and $I_{2}$ inhibitory phases, as Fig. 7 shows. Finally, it should be mentioned again that, in a small proportion of subjects (three in our study), an $E_{1}$ response could be evoked by a stimulus maximal for fast conducting fibres with little, if any, background voluntary contraction being needed to bring the motoneurones to the firing level (Fig. 2).

NATURE AND SITE OF RECEPTORS FOR REFLEX The fibres in the digital nerves arise largely from receptors in the skin and, to a lesser extent, from deeply situated receptors such as those in joint capsules and periosteum. The digital nerves do not contain fibres from muscle spindles and it is unlikely that Golgi tendon organs make a significant contribution, since these structures are usually found at the junction of a muscle belly with its tendon.

To obtain further information concerning the origin of the fibres involved in the reflex activity dèscribed above, two further experiments were devised. In the first experiment the stimulus was a mechanical one and consisted of a series of taps 

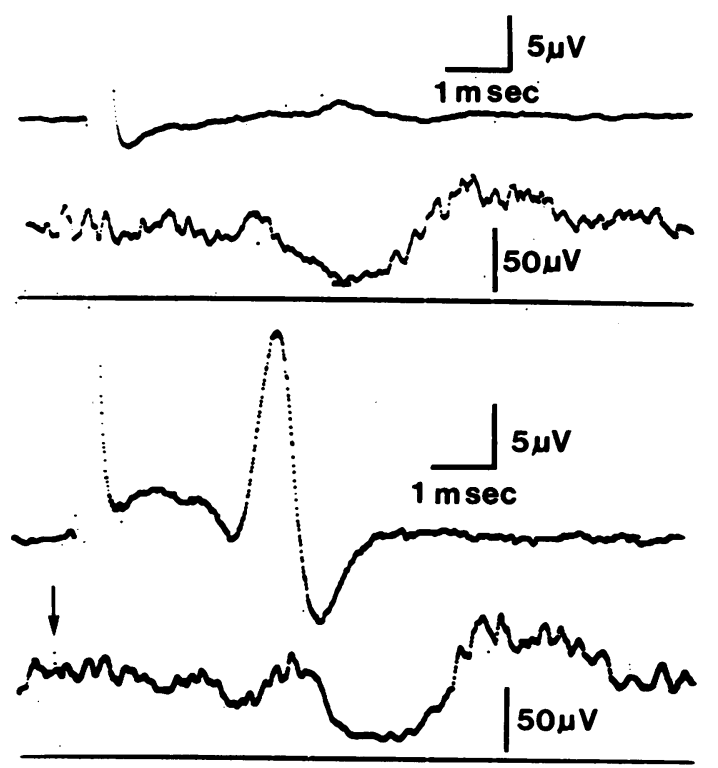

: - -

FIG. 9. Reflex responses of APB muscle after electrical stimulation of tip of index finger or of digital nerve fibres at finger base (upper and lower parts of Figure respectively). The sensory nerve potentials recorded from the median nerve at the wrist are shown above the corresponding averaged responses. The smallest divisions on the time scale represent $10 \mathrm{msec}$.

delivered to different regions of the index finger by an observer using a blunt probe. In the abductor pollicis brevis, it was found that, although the earlier inhibitory and excitatory phases, $I_{1}$ and $E_{1}$, were both absent the later phases, $I_{2}$ and $E_{2}$, were clearly present (Fig. 8). Following $E_{2}$, alternating inhibitory and excitatory waves could also be distinguished (Fig. 8b).

This type of experiment not only showed that mechanoreceptors were capable of eliciting some features of the reflex, but it also provided some information as to the site of the activated receptors. Thus, of the various regions tested on the finger, the tip was by far the most powerful source of reflex activity. It was still possible however, that a substantial part of the force imparted to the finger tip during stimulation would have been transmitted to receptors lying at a distance, in the manner described by Lynn
(1969) for the cat pad. Therefore, in a second type of experiment, stimulus spread was restricted by delivering electric shocks through small disc electrodes attached to either side of the tip of the index finger. From Fig. 9 it can be seen that the full complement of inhibitory and excitatory reflex changes ensued. The corresponding median nerve action potential indicates that the group II fibres which had been excited by electrical $\stackrel{0}{\rightarrow}$ stimulation of the finger tip comprised only some $4 \%$ of those present in the digital nerves at the finger base.

The conclusion from these two experiments is $\stackrel{\mathbb{Q}}{\circ}$ that a large part of the reflex activity described क in this paper can be evoked by stimulation of $\overrightarrow{0}$ those mechanoreceptors in the finger tip which $\overrightarrow{\vec{\omega}}$ are connected to fast-conducting (group II) axons.

OPTIMAL STIMULATION ZONES In the previous section the strong reflex responses elicited in 0 small hand muscles by stimulation of the finge्ठ tip were described. In a further set of experiment8 응 the effects of stimulating widely separated areas of skin were examined. In Fig. 10 the intensitie of the corresponding $\mathrm{I}_{2}$ inhibitory phases have been expressed in terms of the depression 3 voluntary EMG activity during $25 \mathrm{msec}$ epochs. Ф (see Methods section). Figure 10 shows that the $\vec{\theta}$ greatest inhibition was exerted on APB $\omega$ motoneurones by electrical stimulation of the thumb and fingers and by stimulating skin over the elbow (E) and ventral aspect of the forearm (F). In contrast, stimulation of skin in the axilla (A), chest wall (C), ear lobe (L), and the contralateral index finger (II, contra) were all relatively ineffective in producing inhibition, even though the stimuli were large enough to cause pain.

The influence of the zone of stimulation was emphasized more strongly when the latency rather than the intensity of inhibition was measured. For example, when APB was studied the earliest inhibition was observed after stimulation of the thumb. Stimulation of the index, middle, ring, and little fingers evoked inhibitory responses with progressively longer latencies $\frac{D}{2}$ (Fig. 11). When inhibition of EMG activity in the abductor digiti minimi (ADM) was studied, $\sigma$ differences in latency were also observed follow- $N$ ing stimulation of the thumb and fingers. In $\underset{\omega}{ }$ 


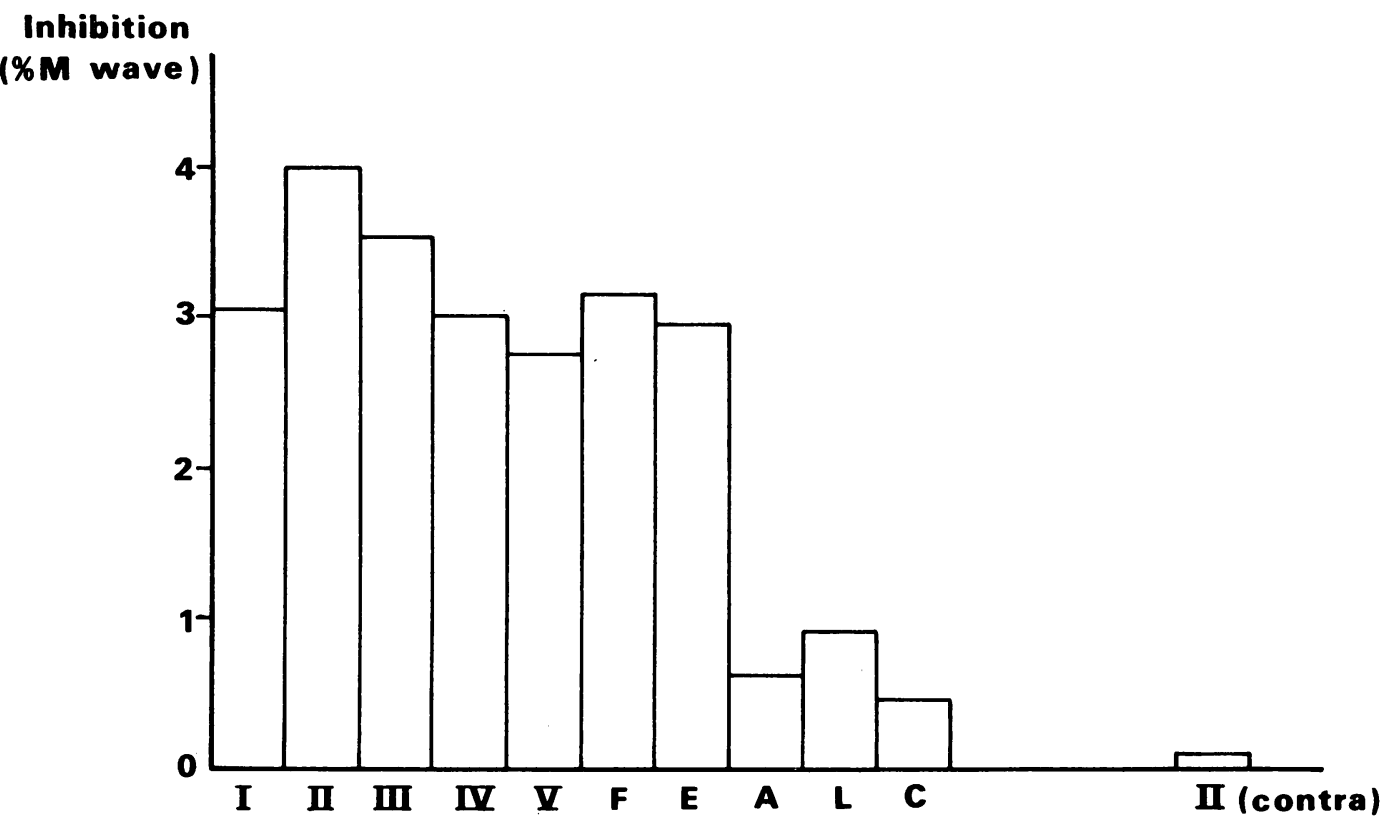

FIG. 10. Amount of $I_{2}$ inhibition produced in APB muscle by strong electrical stimuli applied to various sites. Roman numerals indicate digits of same hand; F, volar aspect of forearm; E, elbow; A, axilla; $\mathrm{L}$, lobe of ipsilateral ear; C, chest wall; II contra, contralateral index finger.

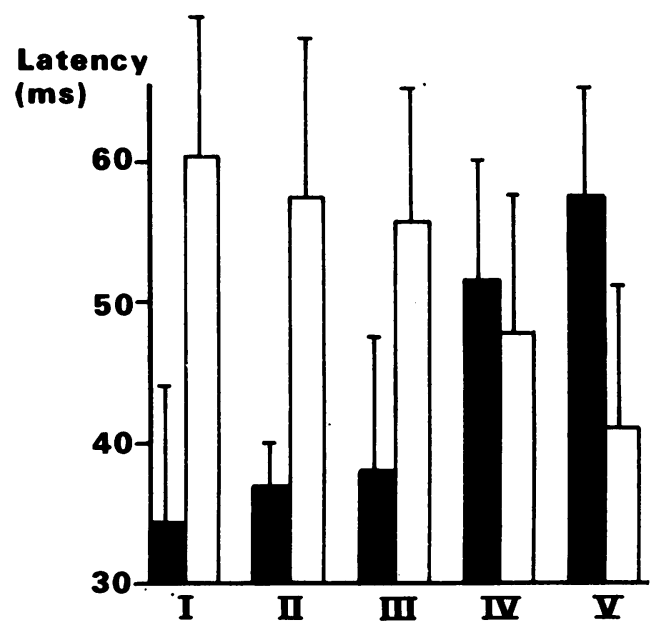

FIG. 11. Latency of the earliest inhibitory phase following electrical stimulation of the thumb (I), index (II), middle (III), ring (IV), and little (V) fingers. Open and filled columns show mean values for abductor digiti minimi and abductor pollicis brevis respectively; vertical bar above each column indicates one standard deviation. contrast with the findings for APB, however, the shortest latency was produced by stimulation of the little finger and progressively later responses came from stimulation of the ring, middle and index fingers and thumb (Fig. 11). The results for ADM resemble those for APB in that stimulation of skin over the forearm or upper arm also yielded inhibition; here again the responses were very much smaller than those evoked by stimulation of the thumb and fingers.

DISTRIBUTION OF REFLEX EFFECTS The effect of single electrical shocks to various areas of skin was studied on several different muscles. The powerful responses elicited in small muscles of the hand by stimulation of the fingers and thumb have already been described. It was found that the same stimuli caused very much smaller effects in more proximal muscles. Examples are given in Fig. 12 in which the EMG responses of the biceps and triceps muscles are shown, together with those of the extensors and long flexor muscles of the fingers. The diminished 

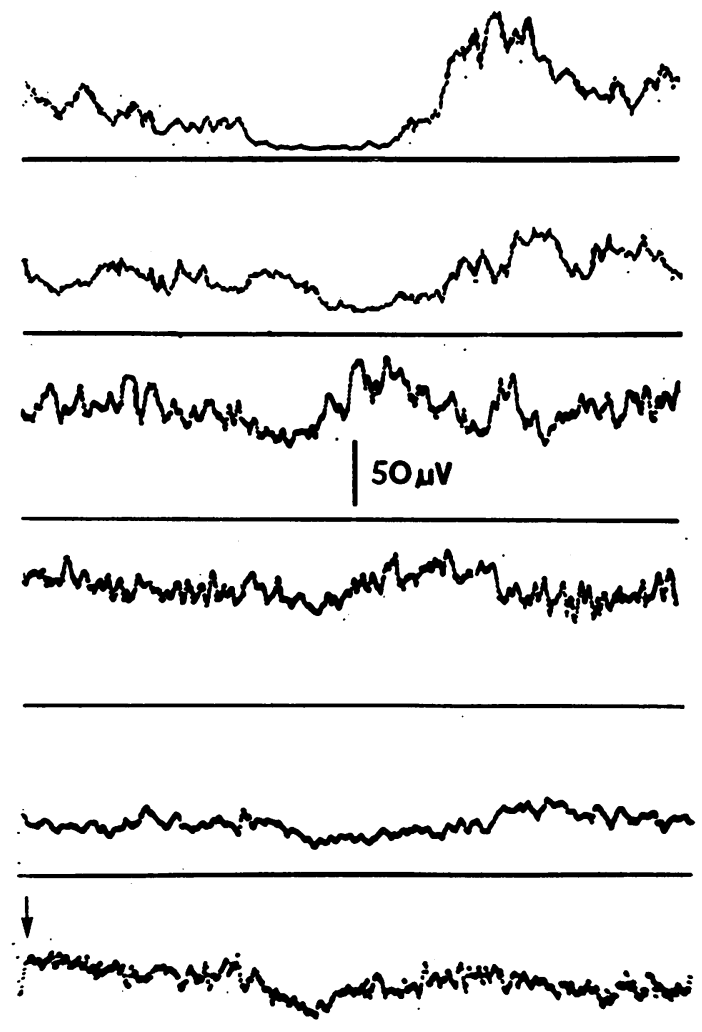

FIG. 12. Distribution of reflex effects in various muscles of the same subject after electrical stimulation of the ipsilateral index finger. From above downwards, the records were obtained from the abductor pollicis brevis, abductor digiti minimi, flexor digitorum muscles, biceps, and triceps. The smallest divisions on the time scale represent 10 msec.

responses of proximal muscles were not a consequence of the remoteness of the stimulated zone for weak effects were still encountered if the stimuli were applied to skin lying directly over the muscle belly.

In addition, the reflex effects which have been studied could be shown to display a type of 'local sign' phenomenon (see Hagbarth, 1952) in that the same stimulus produced differing effects in muscles situated closely together but subserving opposing functions. For example, in Fig. 13 it can be seen that electrical stimulation of the thumb or index finger evoked stronger
A

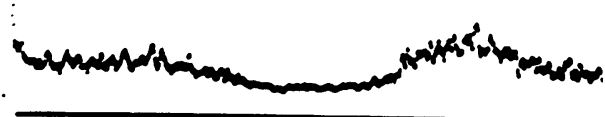

B
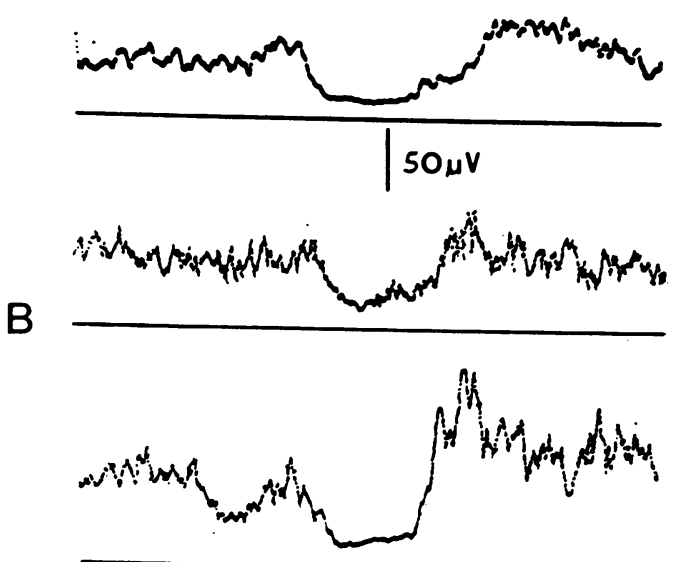

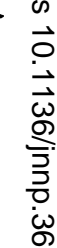

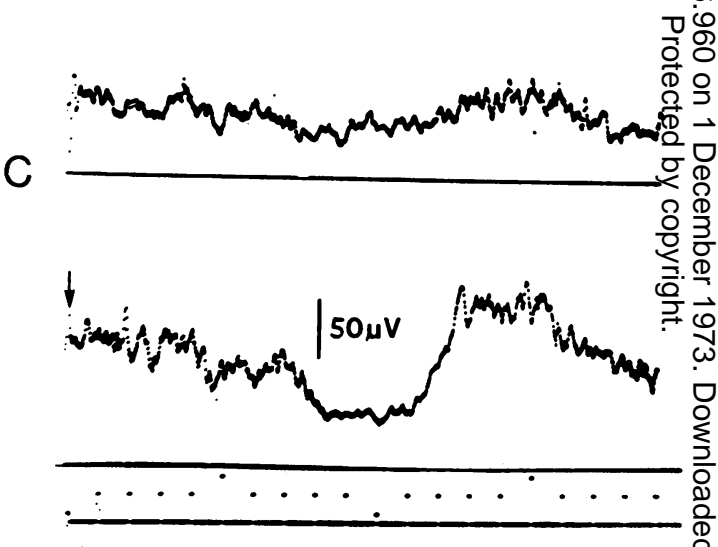

FIG. 13. Effects of same stimuli on muscles with $\stackrel{2}{\Rightarrow}$ antagonistic actions. A. Stimulation of thumb, 음 recordings from adductor pollicis (upper trace of pair) and abductor pollicis brevis (lower trace). B. Stimula tion of index finger, recordings from adductor pollicis (upper trace) and abductor pollicis brevis (lower trace). C. Stimulation of little finger, recordings from? adductor (4th palmar interosseous; upper trace) and 9 abductor digiti minimi (lower trace). Smallest $t_{-0}$. divisions on the time scale represent $10 \mathrm{msec}$.

reflex effects in the short abductor of the thumb을 than in the adductor muscle. Similarly, stimulation of the little finger induced more prominent ${ }^{-}$ responses in the abductor of this digit than in the 0 corresponding adductor muscle. 

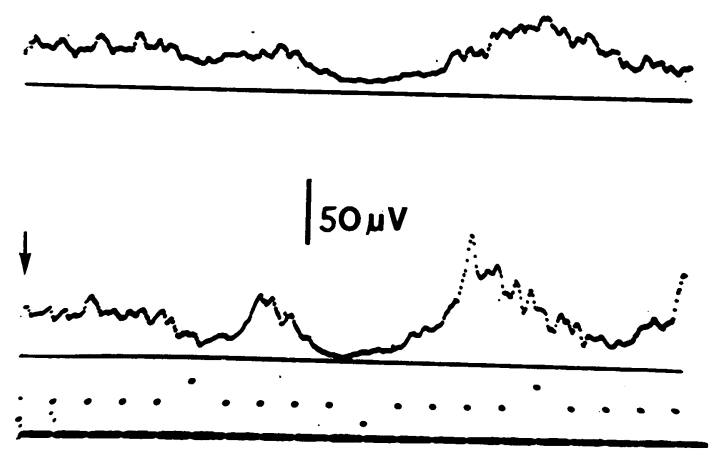

FIG. 14. Responses from the APB muscle after electrical stimuli to index finger which were delivered either regularly (top trace) or irregularly (lower trace). Smallest divisions on time scale represent $10 \mathrm{msec}$.

TIMING OF STIMULI Throughout the series of experiments, it was invariably found that the inhibitory and excitatory reflexes were much larger in response to the first few stimuli than to the succeeding ones. The phenomenon of diminishing responses with regularly repeated stimuli is known to characterize most, if not all, other reflexes and is termed habituation; a careful examination of this phenomenon in man has

\section{4.w.}

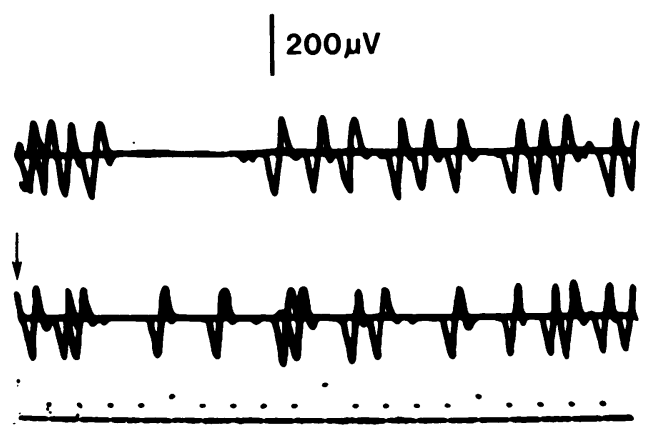

FIG. 15. Discharges of a single motor unit in the abductor pollicis brevis muscle occurring either without a stimulus (upper) or after electrical stimulation of the index or little fingers (middle and lower parts of Figure respectively). For each of the three experiments several oscilloscope traces have been superimposed and some potentials have been retouched. Smallest divisions on the time scale represent $10 \mathrm{msec}$. been reported recently by Dimitrijević et al. (1972).

In the present study an attempt was made to assess the significance of habituation by contrasting, in the same subject, the responses to stimuli repeated every 1.75 seconds with those to stimuli delivered irregularly though with a similar mean interval. Figure 14 shows the results of such an experiment and it can be seen that both the inhibitory and excitatory responses were considerably more marked after irregular stimulation.

SINGLE MOTOR UNIT RESPONSES In a small number of experiments observations were made on single motor units. These experiments provided further information concerning the pattern of motoneurone discharge after a cutaneous stimulus. Figure 15 shows the responses of a single unit in the abductor pollicis brevis after stimulation of the index finger. It can be seen that after the $I_{2}$ inhibitory period is over the same unit begins to discharge again at a time when the $E_{2}$ response normally occurs (90$130 \mathrm{msec})$. So far, we have not seen evidence of units firing during the $E_{2}$ period which had not already been recruited during the background voluntary contraction. This possibility cannot be excluded, however, on the basis of the small number of single units investigated. Of great interest was the finding that some units might be inhibited by stimulation of one digit but not another. Thus in Fig. 15 it can be seen that the unit was strongly inhibited by stimulation of the index finger but much less affected when the shocks were delivered to the little finger instead. Although this observation was not pursued, it indicates that the inhibitory receptive fields for individual motoneurones may be defined quite sharply.

EFFECTS OF LOCAL ANAESTHESIA ON REFLEX ACTIVITY An attempt was made to study the possible role of muscle spindles in the cutaneous reflexes by using local anaesthesia to block fusimotor axons. In one subject with well marked reflexes $20 \mathrm{ml} .0 \cdot 5 \%$ lignocaine hydrochloride solution were injected intravenously after the arm had been rendered ischaemic by an arterial occlusion cuff (Holmes, 1963; Thorne, 1964). After 20 minutes the finger jerk was reduced to 


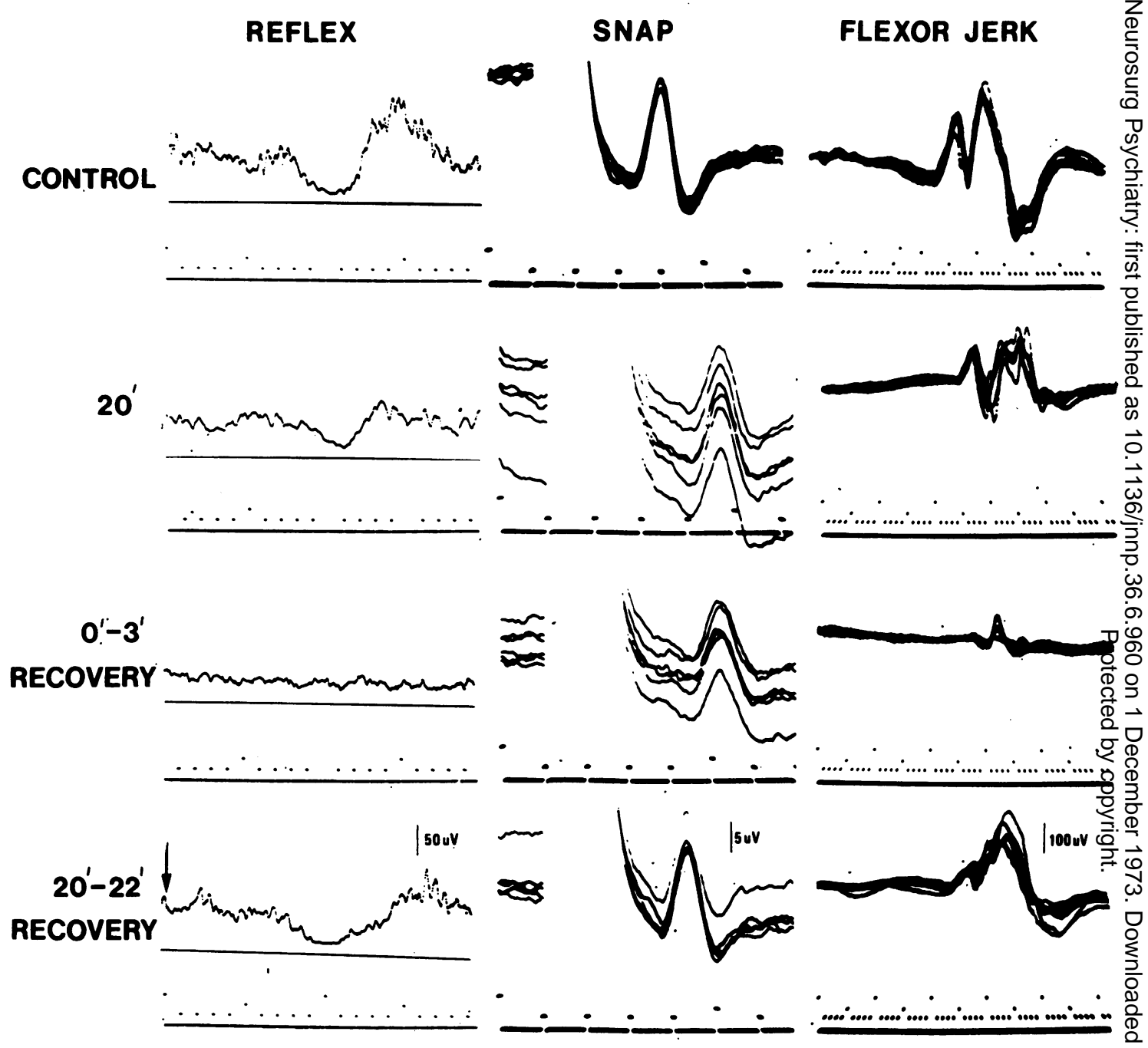

FIG. 16. Effects of local anaesthesia (and ischaemia) on electrically-induced reflex responses in $A P B$ (left hand $\overrightarrow{\vec{A}}$ column), median nerve sensory action potential (middle column) and finger flexor jerk (right hand column). 3 The fingers jerks were elicited by an observer who used a tendon hammer to deliver blows of as uniform force as $\supset$ possible to the semi-flexed fingers. The recordings were made about 20 minutes after the application of the cuff and injection of anaesthetic, and at 0-3 and 20-22 minutes after release of the cuff. The smallest divisions on the time scale represent $10 \mathrm{msec}$ (left hand column), $1 \mathrm{msec}$ (centre and right hand column). For the flexor jerk the $\frac{5}{5}$ vertical bar represents $100 \mu \mathrm{V}$ for the lower record and $50 \mu \mathrm{V}$ for the upper three recordings in the column. Notice the slowing of impulse conduction in the two middle recordings of the centre column.

approximately $50 \%$ of its initial value. At this stage conduction in alpha motor axons appeared to be relatively unimpaired, since strong voluntary contraction could still be made with muscles of the forearm and hand. More significantly, there was little change in the amplitude of the median nerve sensory potential which could be recorded at the wrist after finger stimulation It was therefore probable that the diminution in tendon reflexes resulted from a loss of mechanical $\frac{7}{3}$ sensitivity of the spindles and that this, in turn, signified blockage of impulse activity in fusi- $\Omega$ motor axons. Of great interest, then, was the $\mathbb{O}$ finding that, at the time of tendon reflex de- N 
pression, the $\mathrm{I}_{2}$ and $\mathrm{E}_{2}$ cutaneous reflexes were reduced in size (Fig. 16). A more striking association between the depression of tendon reflexes and late cutaneous reflexes was noticed as the arm recovered from the effects of ischaemia in the first few minutes after release of the arterial occlusion cuff (Fig. 16). The delay in the reappearance of tendon reflexes during this latter period, in spite of rapid recovery of voluntary power, suggested that several minutes were required before the anaesthetic blockage passed off. From Fig. 16 it can be seen that not only did selective anaesthesia appear to abolish $\mathrm{I}_{2}$ and $E_{2}$ but that $I_{1}$ and $E_{1}$ might also disappear. From considerations presented elsewhere (see Discussion section) it is apparent that the latencies of the $I_{1}$ and $E_{1}$ waves are too short for spindles to have been involved in these responses. Instead it seems possible that the relatively small cutaneous sensory axons responsible for these waves may also have been blocked by local anaesthesia together with the fusimotor axons (see below).

\section{DISCUSSION}

The foundations of our knowledge of cutaneous reflexes in mammals were established by Sherrington (1910), who made an extensive study of the hind limb in the decerebrate cat. Sherrington showed that electrical stimulation of a peripheral nerve resulted in flexion of the stimulated limb and extension of the contralateral one. In the ipsilateral limb the excitation of alpha motoneurones to flexor muscles was associated with inhibition of those to extensors. Subsequently, Hagbarth (1952) found, by stimulating areas of skin rather than nerve trunks, that the distribution of excitatory and inhibitory effects was more subtle and purposeful than had been supposed. Hagbarth observed that extensor muscles in the cat could be excited by ipsilateral stimulation, provided the stimuli were applied to the skin overlying the muscle belly; stimuli elsewhere in the limb produced inhibition. The situation for a flexor muscle was in contrast, for the inhibitory field was small and centred over the antagonist extensor muscle; the excitatory field was extensive and covered the remainder of the limb. The organization of these responses made it possible for the limb to be automatically withdrawn from a noxious stimulus wherever the latter was applied. In a later paper Hagbarth (1960) obtained evidence for similar reciprocal relationships for excitatory and inhibitory influences on flexor and extensor motoneurones in man. As in the study on the cat, the observations were made in the lower limb and the stimuli consisted of strong repetitive electrical shocks. It is of interest that when relatively gentle mechanical stimuli are used in animal preparations more discrete reflex effects can be observed. For example, by pressing on the cat pad it is possible to elicit an extensor thrust reflex (Sherrington, 1903), while a tap on a plantar cushion evokes extension of the toes (Engberg, 1964; Egger and Wall, 1971). The advantages of studying cutaneous reflexes in man include not only the ability to observe the responses of an intact nervous system but also the possiblity of searching for reflex modulations of ongoing voluntary activity. The present study differs in several ways from most previous ones in man. It has been concerned with the upper limb and especially with the responses of motoneurones innervating small muscles of the hand. The range of stimuli included not only electric shocks of graded intensity but also mechanical stimuli. In addition, it was possible to ascertain the properties of the activated sensory nerve fibres from inspection of the orthodromically-conducted nerve action potentials.

The study has shown that electrical stimulation can induce both excitatory and inhibitory changes in motoneurones. In their time courses, these changes are remarkably similar to those described by Gassel and Ott (1970) in triceps surae motoneurones after stimulation of the dorsum of the foot. In the present study it was found, by altering the stimulus strength, that two types of inhibition were involved. One type, designated $I_{1}$, had a high threshold and a short latency; the other type $I_{2}$, had a low threshold and long latency.

$I_{1}$ INHIBITION In most subjects the $I_{1}$ inhibition was mediated by fibres having higher thresholds than those responsible for the $I_{2}$ type of inhibition. While some of the $I_{1}$ afferent fibres contributed to the recorded median nerve sensory action potential, others were too small for their impulse activity to be detected. Accord- 
ing to Buchthal and Rosenfalck (1966), the median nerve sensory action potential, recorded at the wrist with surface or coarse needle electrodes, is composed of activity in nerve fibres with diameters of 6-11 $\mu$; these fibres would fall into the type II category of Lloyd and Chang (1948). It follows that the afferent nerve fibres mainly responsible for $I_{1}$ inhibition must have had diameters which were in the lower part of this range or even smaller-that is, group III fibres. If $6 \mu$ is assumed to be the diameter of the largest sensory fibres contributing to $I_{1}$ then these fibres would have impulse conduction velocities of $36 \mathrm{~m} / \mathrm{sec}$ (Hursh, 1939). In a subject with a distance between the base of the middle finger and vertebra prominens of $85 \mathrm{~cm}$, the afferent impulse conduction time would be about $24 \mathrm{msec}$. Similarly, the conduction time from the cervical cord to the small muscles of the hand would be approximately $15 \mathrm{msec}$ on the basis of measurements of $\mathrm{H}$-reflex latency made in these muscles (Upton et al., 1971). This value of $15 \mathrm{msec}$ is the maximum time which would be needed for an impulse which had just been initiated in the axon hillock of the motoneurones, before the arrival of the inhibitory volley in the cord, to travel out to the muscle. It follows that $15 \mathrm{msec}$ is also the maximum (efferent) time before the $I_{1}$ inhibitory phase can be detected in the muscle. The total conduction time for the $I_{1}$ inhibitory phase would be $39 \mathrm{msec}$, which is the sum of the afferent and efferent values, together with any time occupied by transmission in synaptic pathways within the neuraxis. The figure of $39 \mathrm{msec}$ is close to the observed latency of $I_{1}$ inhibition in APB which had a mean value of $35 \pm 4 \mathrm{msec}$ after stimulation of the index finger in the 16 subjects examined. The only estimate of the conduction velocities of cutaneous nociceptor fibres subserving the inhibitory reflex in man is that of Hagbarth (1960) who obtained maximal values of $33-40 \mathrm{~m} / \mathrm{sec}$. In the cat Rosenberg (1970) also found that it was the smaller myelinated fibres which were responsible for the inhibitory postsynaptic potentials in ipsiand contralateral extensor motoneurones. He also deduced that only one interneurone was involved in the ipsilateral reflex pathway within the spinal cord. The present observations concerning $\mathrm{I}_{1}$ inhibition are perfectly compatible with this being the part of the same process as that studied by Hagbarth in man and Rosenberg in the cat. The observations of Hagbarth have been extended, in that this type of inhibition has been shown to involve motoneurones innervatingo small muscles of the hand as well as those supplying larger and more proximal muscles in the lower limb.

$\mathrm{I}_{2}$ INHIBITION The $\mathrm{I}_{2}$ inhibitory phase was thes? most marked of the cutaneous reflexes observedo in the present study. In some respects it was also $\overline{\bar{n}}$ the most intriguing reflex, since its low threshold $\frac{\text { ? }}{\sigma}$ contrasted with its long latency. We are aware of 0 only one previous description of this type of कै inhibition after digital stimulation, that recently $\overrightarrow{0}$ given by Liberson (1973). Although Liberson $=$ recognized the significance of this inhibition in the interpretation of silent periods induced by electrical stimulation of ' mixed' nerve trunk, his? study did not contain an analysis of the receptorso and afferent fibres responsible for this reflex or of the possible synaptic pathways involved. Theo present study has provided evidence to show that the reflex may be initiated by cutaneoळs. mechanoreceptors and that the tips of the fingers and thumb are particularly sensitive regions. From the morphological study of Quilliam apd Ridley (1971) several types of receptors woufd emerge as candidates for the reflex-Merke $\vec{\omega}$ discs, Meissner's corpuscles, Pacinian corpuscles, and free nerve endings. The median nerve action potential recordings showed that the receptors were connected to the fastest conducting fibres and that, in a sensitive subject, the reflex could occur when less than $4 \%$ of these fibres were $\stackrel{\odot}{\Phi}$ excited in a digit. According to Buchthal and $\overrightarrow{\vec{F}}$ Rosenfalck (1966), each of the two digital 3 branches in a finger contains about 1,200 fibres at the level of the second phalanx, although? rather more than one-third of these fibres are branches from other axons. In any event, ito would appear that the $I_{2}$ inhibitory reflex can be elicited in some subjects when as few as 50. mechanoreceptor fibres have been activated.

Since the stimuli capable of inducing $\mathrm{I}_{2} \frac{2}{\circ}$ inhibition are not injurious to the skin, the reflex cannot be considered nociceptive. Never $-\frac{D}{0}$ theless, it seems possible that the reflex may have a protective function. For example, consider a $\sigma$ hand either searching for an object or in- $N$ advertently encountering one without visual 
guidance. Once one of the finger tips makes contact with the foreign surface, there are advantages in pausing, since further movement of the hand would cause tissue damage if other parts of the object were sharp or hot. In contrast, the checking of the hand would enable sufficient time for more discrete and appropriate exploratory movements to be programmed by the nervous system once the range of the target has been established.

The nature of the neural pathway responsible for the long latency of the $I_{2}$ reflex is unknown, but sufficient information is available to justify speculation. The high impulse conduction velocities for the sensory and motor fibres involved in the reflex would leave approximately $55 \mathrm{msec}$ of the reflex latency at threshold unaccounted for. This central time is substantial but is still compatible with activity in a polysynaptic pathway. Thus it is known that the spinobulbospinal reflexes may have a long latency (Shimamura and Livingstone, 1963) and, in the paralysed limbs of patients with completely transected spinal cords, the second component of the flexor withdrawal reflex may not appear for periods of up to $400 \mathrm{msec}$ (Shahani and Young, 1971). It is nevertheless of interest that intracellular recordings from mammalian motoneurones have not so far revealed inhibitory postsynaptic potentials from fast-conducting cutaneous afferent nerve fibres (Rosenberg, 1970) or low-threshold mechanoreceptors (Engberg, 1964), although it is possible that responses with such long latencies might not have been searched for. An alternative proposal for the mechanism of the $\mathrm{I}_{2}$ inhibitory reflex is that it involves the fusimotor system. It is now accepted that during voluntary movements the alpha motoneurones receive an excitatory input from primary endings in the muscle spindle. Abolition of this input, as in the unloading reflex (for example, Angel et al., 1965), will induce a temporary pause in the discharge of the alpha motoneurones. A reduction of spindle assistance will also occur whenever the fusimotor neurones are inhibited and it is known from the work of Hunt and Paintal (1958) in the cat that this may happen after mechanical stimulation of the skin. The question now arises as to whether $55 \mathrm{msec}$ would allow sufficient time for the reduction in spindle assistance to be achieved. A satisfactory answer would require knowledge of conduction velocities of the fusimotor fibres and of the time course of relaxation of intrafusal muscle fibres. Although direct measurements of the latter have not been made in man, the observations of Thorne (1964) on the spindle reflex (S reflex) have provided useful information. He found that strong stimulation of the ulnar nerve at the wrist evoked a response in the first dorsal interosseous muscle with a latency of 36 to $45.5 \mathrm{msec}$ and that moving the point of stimulation to the elbow caused the latency to lengthen. Thorne gave reasons for supposing that these stimuli were strong enough to have excited the fusimotor fibres; the ensuing intrafusal muscle fibre contraction had initiated a volley in the primary spindle afferents which, in turn, had caused monosynaptic excitation of alpha motoneurones.

It is conceivable that the time required for intrafusal muscle fibre contraction to excite primary endings is approximately the same as that for relaxation to halt the sensory discharge. If so, the extra time involved in the $\mathrm{I}_{2}$ reflex, as opposed to the $S$ reflex, would be the cutaneous afferent conduction time (about $15 \mathrm{msec}$ ), the conduction time in proximal segments of the fusimotor fibres (about $16 \mathrm{msec}$ from cord to wrist, assuming a distance of $72 \mathrm{~cm}$ and a conduction velocity of $45 \mathrm{~m} / \mathrm{sec}$; Thorne, 1964), and central time for inhibition of fusimotor neurones (about $2 \mathrm{msec}$ if disynaptic). This extra time would amount to $33 \mathrm{msec}$ and, when added to Thorne's value of $36-45 \cdot 5 \mathrm{msec}$ for the latency of the $S$ reflex after stimulation at the wrist, would yield a theoretical latency of 69$78.5 \mathrm{msec}$ for the $I_{2}$ reflex. This value is of the same order as that observed in the present study.

More direct analysis of the role of the fusimotor system in the $I_{2}$ reflex was attempted by the use of local anaesthesia to block conduction in fusimotor fibres. If it were possible to achieve a voluntary contraction utilizing only the direct descending neural pathway to alpha motoneurones, then, according to the present hypothesis, cutaneous stimulation should no longer produce inhibition. In one subject with prominent cutaneous reflexes who was investigated in this way there was a marked reduction in all components of the cutaneous reflex at a time when impulse activity in the smaller myelinated fibres was thought to be 
blocked (see Results section). If the latencies of the reflexes are also taken into account the disappearance of $\mathrm{I}_{2}$ phase would be compatible with the onset of spindle inactivation, while the diminution in $I_{1}$ and $E_{1}$ reflexes might have resulted from impulse blockage in group III cutaneous afferent fibres (see above). This experimental approach is admittedly indirect but the findings give further inducement for evaluating the contribution of spindles to cutaneous reflexes in man. It is probable that further information on this subject will come from studies employing the single fibre recording technique described by Vallbo and Hagbarth (1968).

$E_{1}$ EXCITATION One important feature of the $E_{1}$ excitatory reflex was that, like the $I_{1}$ response, it usually had a high threshold to electrical stimulation and involved cutaneous afferent nerve fibres with conduction velocities of 35$40 \mathrm{~m} / \mathrm{sec}$. It is of interest that these velocities are similar to those determined by Shahani and Young (1971) for the withdrawal reflex in the leg of a normal subject. This similarity raises the possibility that the $E_{1}$ reflex is itself part of a withdrawal reflex and that the full reflex would have been obtained had strong repetitive electrical stimulation been employed instead. Further evidence in this direction is that the $E_{1}$ response resembled the flexor withdrawal reflex in the leg in displaying a 'local sign' (see Results section).

It had been hoped that the present study would shed further light on the nature of the $\mathrm{V}_{2}$ wave described by Upton et al. (1971). This wave could be recorded during voluntary contraction in various muscles, including those of the hand, after stimulation of the appropriate 'mixed' nerve. Upton et al. considered a number of possible explanations, including reflexes mediated by cutaneous or joint afferents and a postinhibitory rebound in motoneurone excitability (see also Andersen and Sears, 1964). In the experiments of Upton et al. (1971) the latency of the $V_{2}$ wave could fluctuate by up to $10 \mathrm{msec}$ during successive trials in the same subject (see their Fig. 3). Among the population of normal subjects studied by these authors the latencies ranged from 48-65 msec. This range of latencies is very similar to that determined for the $E_{1}$ wave in the present experiments and could indicate a common identity for the $E_{1}$ and $V_{2}$ waves. Thus, in experiments to elicit a $V_{2}$ wave, a stimulus to a 'mixed' nerve trunk, such as the median nerve at the level of the wrist, will produce excitation of cutaneous afferents as well as fibres from muscle, tendon and joint receptors. Against the indentification of the $E_{1}$ wave with the $V_{2}$ response was the absence, in the present study, of any correlation between the sizes of the two waves in the same individual. For example, a given subject might have a very prominent $\mathrm{E}_{1} \frac{\mathrm{\sigma}}{\overline{\mathrm{V}}}$ wave and yet not display a $V_{2}$ response during $\frac{\vec{\sigma}}{\vec{\sigma}}$ voluntary contraction. The most definitive $\stackrel{D}{\circ}$ analysis of the $V_{2}$ wave will undoubtedly come from further observations on patients with $\overrightarrow{0}$ divided dorsal roots.

$\mathrm{E}_{2}$ EXCITATION The $\mathrm{E}_{2}$ type of excitation had a latency of about $120 \mathrm{msec}$ and the recordings from the median nerve indicated that it depended $\stackrel{\omega}{\omega}$ partly on activity in the larger type II sensory 9 fibres in the digital nerves. The experiment 80 using mechanical stimuli further established thai these fibres belonged to cutaneous mechanof receptors. In addition, type III fibres must have्g contributed to these responses, since the wave became larger as the stimulus intensity w increased, even though the median nerve sensory action potential had already reached 1 is maximum size.

In keeping with the interpretation of the $E_{1}$ wave, presented above, one explanation of the $\mathrm{E}_{2}$ ? response would be that it represented the second component of a withdrawal reflex (Shahani and Young, 1971). The latency of the $E_{2} \stackrel{\circ}{\varnothing}$ response also suggests an identity of this wave $\overrightarrow{\vec{P}}$ with the period of greatest increase in excitability $\frac{3}{3}$ of triceps surae motoneurones which Gassel (1970) and Gassel and Ott (1970) were able to? demonstrate in normal subjects after stimulation of the skin in the lower leg and foot. In the present study it was found that, unlike the $E_{1}$; response, the $E_{2}$ potential was never recorded unless there had been an earlier inhibitory period. The possibility cannot be denied, therefore, that

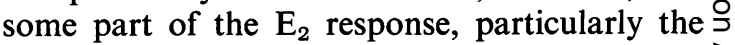
lowest threshold component, was not reflex in $\frac{D}{0}$ origin but merely signalled the synchronous resumption of voluntary activity in the moto- $\widetilde{\sigma}$ neurone pool after inhibition. The increased $N$ excitability of neurones after inhibitory post- $\underset{W}{\mathbb{N}}$ 
synaptic potentials might also make a contribution to this discharge (Andersen and Sears, 1964).

Similarly, there must be some doubt concerning the reflex nature of the alternating inhibitory and excitatory waves which follow $E_{2}$. After the first synchronous post-inhibitory discharge, there will be a tendency for motoneurones to continue to fire in unison, provided that their discharge frequencies are similar. In fact, these frequencies will not be completely identical and hence the electromyographic activity will become progressively smoother as the voluntary contraction continues.

In conclusion, it is clear that the present study has not permitted a complete analysis to be made of the neural substrates underlying the various reflex phenomena which have been described. Nevertheless, the study has shown that inputs from the skin exert a powerful influence on the reflex behaviour of motoneurones and that the nature of this influence is possibly more complex than had previously been supposed. It is hoped that further studies may lead to a more complete understanding of the neurophysiological derangements observed in disease.

We are indebted to Drs. F. Petito and R. E. P. Sica for help with some of the experiments, and to Miss I. Csatari and Mrs. J. English for secretarial assistance. Financial support from the Canadian Medical Research Council to Dr. A. J. McComas is gratefully acknowledged. Mrs J. Leon, who assisted in the preparation of the final manuscript, is paid by the Muscular Dystrophy Association of Canada.

\section{REFERENCES}

Andersen, P., and Sears, T. A. (1964). The role of inhibition in the phasing of spontaneous thalamo-cortical discharge. Journal of Physiology, 173, 459-480.

Angel, R. W., Eppler, W., and Iannone, A. (1965). Silent period produced by unloading of muscle during voluntary contraction. Journal of Physiology, 180, 864-870.

Buchthal, F., and Rosenfalck, A. (1966). Evoked action potentials and conduction velocity in human sensory nerves. Brain Research, 3, 1-122.

Dimitrijević, M. R., Faganel, J., Gregorić, M., Nathan, P. W., and Trontelj, J. K. (1972). Habituation: effects of regular and stochastic stimulation. Journal of Neurology, Neurosurgery, and Psychiatry, 35, 234-242.
Egger, M. D., and Wall, P. D. (1971). The plantar cushion reflex circuit: an oligosynaptic cutaneous reflex. Journal of Physiology, 216, 483-501.

Engberg, I. (1964). Reflexes to foot muscles in the cat. Acta Physiologica Scandinavica. 62, Suppl. 235, 1-64.

Gassel, M. M. (1970). The role of skin areas adjacent to extensor muscles in motor neurone excitability: evidence bearing on the physiology of Babinski's response. Journal of Neurology, Neurosurgery, and Psychiatry, 33, 121-126.

Gassel, M. M., and Ott, K. H. (1970). Local sign and late effects on motoneuron excitability of cutaneous stimulation in man. Brain, 93, 95-106.

Hagbarth, K.-E. (1952). Excitatory and inhibitory skin for flexor and extensor motoneurones. Acta Physiologica Scandinavica, 26, Suppl. 94.

Hagbarth, K. E. (1960). Spinal withdrawal reflexes in the human lower limbs. Journal of Neurology, Neurosurgery, and Psychiatry, 23, 222-227.

Holmes, C. McK. (1963). Intravenous regional analgesia. A useful method of producing analgesia of the limbs. Lancet, 1, 245-247.

Hunt, C. C., and Paintal, A. S. (1958). Spinal reflex regulation of fusimotor neurones. Journal of Physiology, 143, 195-212.

Hursh, J. B. (1939). Conduction velocity and diameter of nerve fibers. American Journal of Physiology, 127, 131-139.

Liberson, W. T. (1973). Silent periods and widespread inhibition in man. In Proceedings of the 4th International Congress of Electromyography, Brussels, 1971.

Lloyd, D. P. C., and Chang, H. T. (1948). Afferent fibers in muscle nerves. Journal of Neurophysiology, 11, 199-207.

Lynn, B. (1969). The nature and location of certain phasic mechanoreceptors in the cat's foot. Journal of Physiology, 201, 765-773.

Merton, P. A., (1954). Voluntary strength and fatigue. Journal of Physiology, 123, 553-564.

Quilliam, T. A., and Ridley, A. (1971). The receptor community in the finger tip. Journal of Physiology, 216, 15 $\mathrm{P}-$ $17 \mathrm{P}$.

Rosenberg, M. E. (1970). Synaptic connexions of alpha extensor motoneurones with ipsilateral and contralateral cutaneous nerves. Journal of Physiology, 207, 231-255.

Shahani, B. T., and Young, R. R. (1971). Human flexor reflexes. Journal of Neurology, Neurosurgery, and Psychiatry, 34, 616-627.

Sherrington, C. S. (1903). Qualitative difference of spinal reflex corresponding with qualitative difference of cutaneous stimulus. Journal of Physiology, 30, 39-46.

Sherrington, C. S. (1910). Flexion-reflex of the limb, crossed extension-reflex, and reflex stepping and standing. Journal of Physiology, 40, 28-121.

Shimamura, M., and Livingston, R. B. (1963). Longitudinal conduction systems serving spinal and brain-stem coordination. Journal of Neurophysiology, 26, 258-272.

Thorne, J. (1964). Reflex responses in man evoked by gamma efferent activation. Nature, 203, 612-613.

Upton, A. R. M., McComas, A. J., and Sica, R. E. P. (1971). Potentiation of 'late' responses evoked in muscles during effort. Journal of Neurology, Neurosurgery, and Psychiatry, 34, 699-711.

Vallbo, §̊, B., and Hagbarth, K.-E. (1968). Activity from skin mechanoreceptors recorded percutaneously in awake human subjects. Experimental Neurology, 21, 270-289. 